\title{
Informação e planejamento familiar como medidas de promoção da saúde
}

\author{
Information and family planning \\ as measures of health promotion
}

Escolástica Rejane Ferreira M oura 1

Raimunda M agalhães da Silva 2

1 Secretaria da Saúde do Ceará.

Av. Filomeno Gomes 80/401, Jacarecanga, 60010-280, Fortaleza CE.

escolpaz@yahoo.com.br

2 Universidade de Fortaleza

(Unifor).

\begin{abstract}
This is an evaluation research with quantitative and qualitative approaches that had for objective to describe the obstacles related to the offer of information in family planning (FP) / birth-control methods (M ACs); to identify the responsible actors for this activity; to lift the knowledge of the clientele about M ACs and the notion that this has regarding the importance of planning the family. The data were collected by interviews and free observation in an area of Ceará. The results described a practice of giving information in FP centered in the individual orientation and group or collective activities being accomplished sporadically, which most of the nurses attributed to the overload of tasks and the high number of people linked to a Team of Family Health (TFH); the doctors' absence in someTFH, overloading the nurse; and the lack of support matters and of an appropriate physical space. The pill, the masculine preservative and the injetable were M ACs more acquaintance from the interviewed women, proceeded by DIU, the table and the maternal suckling. Even so, the need of larger popularization of those information was verified. We stood out the singular perceptions described by the women's group, keeping informations of quite wide sense on the benefits of FP.
\end{abstract}

Key words Family planning, Evaluation, Information in health, Health promotion
Resumo Trata-se de pesquisa de avaliação com abordagens quantitativa e qualitativa que teve por objeti vo descrever as barreiras relacionadas à oferta de informações em planejamento familiar (PF) / métodos anticoncepcionais (M ACs); identificar os atores responsáveis por esta atividade; levantar o conhecimento da clientela sobre os M AC s e a noção que esta tem a respeito da importância de planejar a família. Os dados foram coletados por meio de entrevista e observação livre em uma região do Ceará. 0 s resultados descreveram uma prática de dar informação em PF centrada na orientação individual e atividades grupais ou col etivas sendo realizadas esporadicamente, o que a mai oria dos enfermeiros atribuiu à sobrecarga de tarefas e ao elevado número de pessoas vinculado a uma Equipe de Saúde da Família (ESF); a ausência de médicos em algumas ESF, sobrecarregando o enfermeiro; ea escassez de matérias de apoio e de um espaço físico apropriado. A pílula, o preservativo masculino e o injetável foram os M ACs mais conhecidos das mulheres entrevistadas, seguidos pelo DIU, a tabela e 0 aleitamento materno. M esmo assim, ficou constatada a necessidade de maior divulgação dessas informações. Ressaltamos as percepções singulares descritas pelo grupo de mulheres, guardando informações de sentido bastante amplo sobre os benefícios do PF.

Palavras-chave Planejamento familiar, Avaliação, Informação em saúde, Promoção da saúde 


\section{Introdução}

Até o final dos anos 70 as lutas em prol da saúde reprodutiva das mulheres encontraram fortes barreiras, destacando-se o Estado autoritário que não atendia às necessidades básicas da maioria da população; a hegemonia biomédica na construção de representações sobre o corpo feminino e o lugar social da mulher; e os programas verticais de planejamento familiar (PF), implementados por organismos internacionais desde a década de 1960 (Ávila e Corrêa, 1999). Estas autoras enfatizam que por inúmeras vezes as feministas enfrentaram a ordem médica e os "planejadores familiares" numa relação conflituosa, a reivindicar direitos sexuais e re produtivos, apesar de o Brasil ser um país marcado por desigualdades sociais, machismo e governo autoritário.

Contudo, a partir da década de 1980, deuse início, no País, a um período de transição democrática caracterizado pela organização de movimentos sociais, com destaque do movimento feminista, no qual as mulheres passaram a reivindicar direitos relacionados à saúde reprodutiva, incluindo o planejamento familiar, a democratização da educação para a saúde e outras medidas que iam além da esfera biomé dica, abrangendo, portanto, a perspectiva da promoção da saúde e de melhor qualidade de vida (Tyrrell \& Carvalho, 1995).

As atividades de informação em saúde reprodutiva tiveram amplo desenvolvimento na etapa inicial de implantação do Programa de Assistência Integral à Saúde da Mulher (PAISM )/1985, quando o M inistério da Saúde (MS) promoveu treinamentos para profissionais de serviços sobre este enfoque, distribuiu materiais educativos - fitas de vídeo, álbuns seriados, cartilhas, folhetos e outros -, para estimular o desenvolvimento de atividades informativas inovadoras, participativas, ilustrativas e mais atrativas. Vivenciamos esta realidade como enfermeiras assistenciais e de ensino. Todavia, tal ação parece ter sofrido uma descontinuidade ao longo dos anos, mantendo-se tão somente o discurso de que é fundamental como medida de promoção da saúde, porém pouco concretizada e executada nas unidades de saúde e no seio da comunidade.

Em se tratando de PF, as atividades de informação são extremamente relevantes, diríamos indispensáveis, ao alcance dos objetivos de serviços e usuários, exigindo dos profissionais de saúde atitude de empenharem-se em bem in- formar para que a clientela conheça as alternativas de concepção e anticoncepção disponíveis e, assim, possa participar ativamente da definição e do alcance de suas metas reprodutivas.

U ma pesquisa de âmbito nacional, abrangendo demografia e saúde (PNDS-1996) demonstrou aumento na prevalência do uso de M ACs nos últimos 10 anos, passando de $65,8 \%$ para $76,7 \%$, entre 1986 e 1996. Entretanto, ape sar de essa prevalência se mostrar similar à dos países desenvolvidos, não significa boa qualidade dos serviços de PF oferecidos no País, uma vez que, de todas as mulheres unidas em idade fértil ( $15-49$ anos), 40,1\% estavam laqueadas, em 1996; $20,7 \%$ usavam hormonais orais, $1,2 \%$ usavam hormonais injetáveis e 1,1 \% tinha o dispositivo intra-uterino (DIU) inserido. Com relação ao Ceará, a mesma pesquisa revelou que $64 \%$ das mulheres unidas entre 15 e 49 anos usavam al gum M AC, sendo que $32 \%$ destas estavam laqueadas, $20 \%$ usavam pílula e $4 \%$ usavam preservativo masculino, não fugindo, portanto, à realidade nacional. Cabe acrescentar que a maioria das laqueaduras, tanto no âmbito nacional quanto no contexto estadual, ocorreu por ocasião do parto do último filho, nascido através de cesariana sem critério técnico-científico que a justificasse, tão somente para garantir a laqueadura. A cada cinco esterilizações no País, quatro foram realizadas durante cesariana, com variações de $43 \%$ na região Nordeste e 74\% no Estado de São Paulo, elevando a taxa de cesariana do País para uma das maiores do mundo (Sociedade Civil Bem-Estar Familiar - Bemfam, 1996). Neste contexto, Costa (2002) acrescenta que estudos dedicados ao arrependimento pós-laqueadura estabelecem uma relação direta entre este sentimento e a desinformação sobre outros métodos.

Em face do exposto, são fortes os indícios de negligência quanto a informar em PF, constatação que conduziu a elaboração dos seguintes questionamentos: Quais barreiras estariam relacionadas com a oferta de informação sobre os M ACs? Q uem estaria levando estas informações à clientela? Qual o conhecimento dos usuários sobre os M ACs e quais são suas noções quanto à importância de planejar o número de filhos?

Encontramos em Bruce (1990) que a informação dada ao cliente se constitui em elemento da qualidade do PF, aspecto que a autora defende em sua estrutura conceitual - "Q ualidade do cuidado em planejamento familiar". Para Bruce (1990), informar o cliente em PF 
envolve três componentes principais: 1) proporcionar aos clientes a apreciação dos M ACs e de suas principais características; 2) seu emprego eficaz de modo a reconhecer que o método pode provocar alterações físicas saudáveis ou não saudáveis e interferir em atividades cotidianas, inclusive na sexualidade do casal; e 3) desenvolver no cliente uma expectativa apropriada a respeito do que o serviço de saúde oferece e garante. A mesma autora, apropriandose de estudo desenvolvido por Berelson (1966), assinala que, se os clientes não retiverem a informação do uso correto do M AC, não podem cumprir com as exigências dos métodos em uso; e se um método como o DIU não é explicado suficientemente e seus efeitos potenciais apreciados, é mais provável que o usuário interrompa o uso.

Portanto, reconhecendo a importância da informação para uma prática consciente, saudável e efetiva da clientela em PF, como medida de promoção da saúde, decidimos pela realização do presente estudo que tem os seguintes objetivos: avaliar as barreiras relacionadas à oferta de informações em PF / M ACs; identificar os atores responsáveis por esta atividade; $\mathrm{e}$ avaliar o conhecimento da clientela sobre os M ACs e a noção que esta tem a respeito da importância de planejar a família.

\section{Materiais e método}

Trata-se de estudo de abordagem quantitativa e qualitativa, do tipo pesquisa de avaliação. Na visão de García-Núñes (1993), éo tipo de pesquisa que, aplicada na área de PF, mostra o que funciona e o que não funciona, o que devemos manter ou mudar, constituindo-se em um instrumento para a tomada de decisão. Portanto, a avaliação a que nos propomos parece adequada para encontrar respostas às indagações levantadas.

A pesquisa foi realizada em áreas urbanas e rurais dos municípios de Aratuba, Mulungu, Guaramiranga, Pacoti, Baturité, Itapiúna, Capistrano eAracoiaba de uma Regional do Sistema de Saúde do Ceará. Esta regional possui uma população de 122.933 habitantes, da qual 30.345 são mulheres em idade fértil, na faixa etária de 15 a 49 anos (SES-CE, 2003).

Trabalhamos com uma amostra de $29(90,6 \%)$ dos enfermeiros da região e 50 usuárias, número delimitado pela saturação das falas, ou seja, identificando a repetição dos dados de forma a não mais aportar informações novas ao con- texto da entrevista, encerramos como adequada (Trentini \& Paim, 1999).

Os enfermeiros e as usuárias foram selecionados com base nos seguintes critérios de elegibilidade: a) enfermeiros - estarem atuando na assistência ao planejamento familiar como membro de equipe de PSF; e b) usuárias(os) mulheres ou homens participantes ou desejosas(os) de participar do serviço de planejamento familiar.

Os dados foram coletados no período de julho a setembro de 2003, por meio de entrevista estruturada e observação livre. As entrevistas foram realizadas, em sua maioria, nas Unidades de Saúde da Família (USFs) e outras, especificamente com enfermeiros, foram realizadas em seus domicílios. Estas seguiram dois roteiros: um destinado aos enfermeiros e 0 outro dirigido aos usuários. As falas foram anotadas pela pesquisadora ao longo das entrevistas. A observação livre nos conduziu a conhecer os atos, a dinâmica espontânea dos indivíduos, sua prática e seu cotidiano, possibilitando aprofundar a compreensão do fenômeno investigado. Os dados provenientes da observação foram registrados em um diário de campo.

Utilizamos o M étodo de Análise de Conteúdo, seguindo a técnica de análise categorial proposta por Bardin (1977). Vivenciamos as fases de pré-análise, exploração do material e inter pretação. Na pré análise, organizamos os dados pelo uso da lógica, da intuição e das experiências e conhecimentos acumulados, sistematizando as idéias iniciais por repetidas leituras dos conteúdos, identificando pontos de semelhanças e divergências, permitindo agrupar os dados por temáticas oriundas de sentimentos ou ações expressas pelos sujeitos. $\mathrm{Na}$ fase $\mathrm{da}$ exploração do material, realizamos as operações de codificação ou enumeração. Para facilitar a contagem dos eventos, numeramos os rotei ros das entrevistas das usuárias de 01 a 50 e dos enfermeiros de 01 a 29. As informações fornecidas pelos enfermeiros foram codificadas pela letra " $E$ ", enquanto as das usuárias foram codificadas pela letra " $U$ ". Fizemos uma leitura fragmentada de todo material, com a intenção de dividi-lo em unidades de significados convergentes e divergentes, originando as categorias: dinâmica de informar a cliente em PF; conhecimento de usuárias dos serviços de PF quanto aos M ACs; e opiniões destas usuárias quanto à importância do PF.

$\mathrm{Na}$ interpretação, tratamos os resultados brutos de maneira a serem significativos e váli- 
dos. Operações estatísticas simples, do tipo fre qüência absoluta efreqüência relativa permitiram estabelecer tabelas, as quais sintetizaram e consolidaram de maneira objetiva as informações fornecidas para a análise.

O projeto de pesquisa foi aprovado pelo Comitê de Ética em Pesquisa (Comepe) do Complexo Hospitalar da Universidade Federal do Ceará. Aos participantes foi apresentado o termo de consentimento livre e esclarecido, garantida a confidencialidade e a privacidade, a proteção da imagem, a não-estigmatização e a não-utilização das informações em prejuízo das pessoas e/ ou das comunidades.

A pesquisa teve apoio financeiro e logístico da Fundação Cearense de Apoio ao Desenvolvimento Científico e Tecnológico (Funcap), da Célula Regional de Saúde de Baturité e do Programa de Pós-graduação em Enfermagem da UFC.

\section{Resultados \\ Dinâmica de informar a cliente sobre PF}

Dentre os enfermeiros instados a falar sobre as atividades que desenvolvem na assistência ao planejamento familiar, $15(51,7 \%)$ destacaram a consulta de enfermagem com seu componente de orientação individual; outros 14 (48,3\%) enfatizaram realizar, além da consulta de enfermagem, trabalhos com grupos, porém reconhecendo realizarem esporadicamente. Apenas $2(6,9 \%)$ enfermeiros afirmaram manter estas atividades sistematicamente: realizo orientação em grupo sempre antes do atendimento (E5); faço reunião mensal (E15); e outra enfermeira referiu estar planejando um curso, pois acredita ser uma atividade mais impactante ao aprendizado dos clientes: Numa palestra as informações são pouco assimiladas, um curso é mais apropriado. Pretendo abordar a sexualidade, o conhecimento do corpo, a fecundação... para elas realmente decidirem (E14).

A maioria dos enfermeiros atribuiu a baixa freqüência ou a não-real ização das atividades de informação grupal à sobrecarga de tarefas e ao elevado número de pessoas vinculado a uma equipe de PSF. Vinte e um $(72,4 \%)$ enfermeiros consideraram as demandas extremamente elevadas e somente $8(27,6 \%)$ consideraram as demandas razoáveis, coincidindo com os que tinham entre 600 e 800 famílias cadastradas. No cenário do estudo, $12(41,4 \%)$ enfermeiros tinham entre 600 a 800 famílias; $5(17,2 \%)$ en- tre 900 e 1.000 famílias; 8 (27,6\%) tinham de 1.100 a 1.400 famílias e outros $4(13,8 \%)$ tinham de 1.700 a 1.900 famílias. N este sentido, o M S preconiza que cada equipe do PSF seja multiprofissional, constituída por um médico generalista (com conhecimento de clínica geral), um enfermeiro, um auxiliar de enfermagem, de 4 a 6 agentes comunitários de saúde e uma equipe de saúde bucal para cada duas equipes de PSF, constituída por um cirurgiãodentista, um atendente de consultório dentário e um técnico em higiene dental. Cada equipe deve acompanhar entre 600 e 1.000 famílias, não ultrapassando o limite máximo de 4.500 pessoas (M S, 2001). Portanto, com base na determinação do MS, reconhecemos que 12 equipes vêm trabalhando com uma população superestimada, sem desconsiderar o fato de que 1.000 famílias já é um contingente elevado de pessoas para uma equipe acompanhar.

$N$ as falas apresentadas a seguir, os enfermeiros evidenciaram esse desafio com o qual convivem cotidianamente:

É uma área muito grande para a gente dar conta. Aqui deveriam ser oito equipes (quando são quatro) e acaba que a gente não atende com a qualidade que a gente quer (E1, E15, E18).

A alta demanda e o grande volume de programas que temos que oferecer simultaneamente deixa um tempo bem reduzido para o planejamento familiar (E7).

0 número de famílias ultrapassa muito e eu não tenho como atender com qualidade. D everiam ser no máximo 600 famílias (E11).

Se o número de famílias fosse menor, a qualidade do nosso trabalho melhoraria muito. A demanda é muito alta (E3, E16, E27).

Outro agravante apontado pelos enfermeiros foi a ausência de médicos nas equipes, 0 que é até mesmo um problema de abrangência nacional. Sete equipes do universo da pesquisa estavam sem o referido profissional e em uma equipe o médico só atuava duas vezes por semana. Essa realidade contribui para maior sobrecarga de trabalho para o enfermeiro. No Ceará, existem, atualmente, 1.618 equipes habilitadas, das quais 1.258 em funcionamento. As outras 441 estão inativas por falta de médicos (Lopes, 2003).

Percebemos, então, predominância do atendimento individual, centrado em consulta, distanciando-se do enfoque mais coletivo, queéa proposta do PSF. A prática de dar informação em PF centrada no individual é relevante ao se estabelecer um processo de orientação, porém 
tem limitado poder de alcance. 0 referido Programa convida os profissionais a assumirem a co-responsabilidade pela saúde de uma população adstrita, constituída por pessoas de condições de vida homogênea, expostas aos mesmos riscos de adoecer ou morrer, o que favorece a implementação das medidas coletivas em saúde para 0 alcance de metas mais abrangentes, voltadas para as causas reais dos agravos, priorizando ações de promoção e prevenção (M S, 1998). Essa mudança paradigmática de atuação talvez favorecesse a que enfermeiros adotassem com maior abrangência as atividades de informação no PF. A respeito do trabaIho com grupos, Bechelli e Santos (2002) defendem como uma oportunidade para as pessoas adquirirem condições de desenvolverem suas próprias escolhas e mudanças. Os autores enfatizam que, no grupo, a interação é particularmente realizada entre os participantes, os quais pouco a pouco passam a assumir papel ativo no decorrer do processo, decidindo sobre a prioridade dos assuntos que querem discutir. Neste contexto, a força para a mudança provém dos participantes do grupo. Um indivíduo motivado fortalece a disposição do outro para engajar-se de forma mais efetiva na busca da transformação.

Durante a pesquisa de campo, assistimos a uma explanação sobre o Programa de Educação em Saúde e M obilização Social (PESM S), proposta que está sendo implementada na região do estudo. 0 PESM S defende uma ação de educação em saúde de forma contínua a partir de critérios epidemiológicos e ambientais, compatível com as causas dos agravos ao processo saúde-doença, com a participação de lideranças comunitárias, o que pareceu bastante promissor (diário de campo).

Dois outros aspectos que pareceram desestimular os profissionais à realização de atividades grupais foram: a escassez de material de apoio e a falta de um ambiente físico adequado. Apenas $10(34,5 \%)$ enfermeiros afirmaram dispor de álbum seriado, e $1(3,4 \%)$ disse que, apesar de não dispor deste recurso, tomava-0 por empréstimo de outra equipe (E3). Folhetos ou cartilhas para reforçar 0 aprendizado das usuárias e complementar as informações passadas no atendimento individual ou grupal estavam disponíveis em somente 4 (13,8\%) das USFs em quantidade bastante insuficiente. As cartilhas disponíveis haviam sido repassadas ao serviço pela SES-CE ainda em 2000, levandonos a inferir que estas não vinham sendo entre- gues aos clientes. Apenas $5(17,2 \%)$ dos enfermeiros possuíam um conjunto demonstrativo de M ACs, sendo que apenas $1(3,4 \%)$ se encontrava exposto para a visualização da clientela; e somente $1(3,4 \%)$ disponibilizava modelos peniano e uterino.

Por outro lado, chamou-nos a aten ção o fato de que al guns recursos não estavam sendo usados, como televisor, vídeo e fitas cassete. Um enfermeiro até comentou: aqui tem televisão, mas eu nem sei se funciona! (E18), passando a idéia de desinteresse com relação a usar 0 equipamento. Percebemos, ainda, que alguns enfermeiros identificaram a SES-CE como a fonte de suprimento de materiais informativos e de apoio à informação, o que ficou caracterizado no depoimento: Não dava para a Secretaria da Saúde mandar para os municípios um kit de métodos, um álbum seriado e aqueles modelos de borracha? (E6).

Constatamos que praticamente inexistiam áreas físicas adequadas para o desenvolvimento de atividades de orientação / informação em saúde. A quase totalidade das USFs segue um mesmo padrão (pequena sala de espera, dois consultórios, uma sala de procedimentos e banheiros) construído à época do funcionamento do modelo biomédico, centrado na consulta e no atendimento individual. M esmo assim, $6(20,7 \%)$ enfermeiros afirmaram que improvisavam a atividade grupal no consultório (3) ou na sala de espera (3).

Estamos de acordo, portanto, com outro estudo realizado nesta mesma Ceres, o qual identificou que as atividades de informação em saúde reprodutiva, principalmente em grupo, não vinham sendo realizadas pelas equipes de PSF, por algumas razões: insuficiente cobertura da população por equipes de PSF e um elevado contingente de pessoas por equipe; expectativa da população por consulta; ausência ou inadequação de área física para o desenvolvimento de atividades; insuficiência de material educativo; e despreparo dos profissionais para realizar as referidas atividades, o que foi afirmado com base na escassa troca de experiências entre os participantes; orientação pouco direcionada às necessidades do grupo; uso freqüente de linguagem científica; repasse de informações desatualizadas; e utilização inadequada do material de apoio (M oura \& Sousa, 2002).

Queremos, pois, chamar a atenção para as oportunidades perdidas de informação que os enfermeiros estão criando em suas práticas. A educação em saúde é al go que vai mais além, 
convocando profissionais e serviços a oferecer condições para que as pessoas desenvolvam o senso de responsabilidade, tanto por sua própria saúde, como pela saúde da comunidade, mudando os comportamentos sociais, políticos e culturais. Sobre o assunto, Kawamoto (1993) e Levy (2000) ressaltam que as ações educativas em saúde são processos que objetivam capacitar indivíduos ou grupos, de modo que possam assumir ou ajudar na melhoria das condições de saúde da população. Portanto, para melhorar a qualidade no repasse de informações às usuárias, é preciso promover medidas concre tas para modificar a prática que vem sendo desenvolvida.

D as mulheres convocadas a falar sobre as atividades de assistência ao PF que recebiam, $41(82 \%)$ mencionaram a consulta de enfermagem; 29 (58\%) referiram o atendimento médico; $7(14 \%)$ citaram a orientação grupal na USF; e somente $2(4 \%)$ referiram a orientação extramuros, ou seja, fora do espaço da USF. Portanto, as usuárias reforçaram a escassez de atividades grupais voltadas à informação em saúde, aspecto descrito anteriormente pelos enfermeiros.

$\mathrm{N}$ as falas das mulheres apresentadas a seguir é perceptível a escassez de informações, denunciada por 15 (30\%) entrevistadas e, ain$\mathrm{da}$, a descontinuidade com que são realizadas.

Falta divulgação. Eu não procuro o serviço e o serviço também não me procura (U1).

N unca procurei essas coisas (U3, U 23 e U 50).

Falta informação adequada para a compreensão e escolha dos métodos. Não explicam nada, só entregam e pronto. Se eu fosse uma pessoa desinformada poderia até ocorrer um erro (U 13, U25, U 37).

Antigamente tinha palestra, era um planejamento familiar bom, mas sinceramente não está mais tendo (U 32).

Aqui é assim: está aqui a receita, vá ali pegar, nem olham pra a cara da gente (U 39).

Apesar da constatação da baixa oferta de atividades grupais ou coletivas de informação em saúde e das dificuldades que as circundam, 40 (80\%) usuárias apontaram o enfermeiro como o provedor de informações sobre os M ACs (orientação individual como parte da consulta de enfermagem), seguido do agente de saúde, citado por 14 (28\%); amigas ou vizinhas foram referidas por 12 (26\%) das entrevistadas; médicos por $9(18 \%)$ e professores por $6(12 \%)$. Outras fontes relatadas foram: leitura, por 5 (10\%); pessoa da família, por 4 ( $8 \%$ ), tendo sido a mãe citada por $3(6 \%)$; a televisão foi citada por outras 3 (6\%); a auxiliar de enfermagem por 1 (2\%); e 1 (2\%) usuária citou atividade na igre ja. Podemos observar nesses dados que as mulheres têm tido diferentes canais para obter informações sobre os métodos anti concepcionais e que o enfermeiro foi o profissional que mais se destacou como veículo dessas informações no âmbito dos serviços de saúde. No entanto, é importante avaliar o quanto estas informações estão sendo suficientes para garantir a escolha adequada e o uso correto do M AC, bem como proporcionar a possibilidade de troca, a busca por outras fontes de suprimento e outras medidas de autocuidado e de tomada de decisão. Sobre o assunto, Bruce (1990) enfatiza que o usuário informado deve ter habilidade para trocar de M AC, particularmente se é usuário de primeira vez, o que a autora considera medida-chave para satisfação do cliente e a continuidade do uso do método em longo prazo.

\section{Conhecimento de usuárias dos serviços de PF quanto aos MACs}

Esta etapa da pesquisa representou uma oportunidade de informação para as usuárias, na medida em que explicávamos cada M AC para que elas o reconhecessem ou não. É tanto que uma usuária destacou: Era tão bom que as pessoas daqui explicassem tudo direitinho. Como a senhora está fazendo agora, pra gente conhecer todos os métodos e saber escolher (U 39).

Na tabela 1, consolidamos o conhecimento das usuárias a respeito dos diferentes MACs reversíveis.

Conforme demonstrado na tabela 1 , os M ACs mais conhecidos pelas mulheres foram a pílula, o preservativo masculino e o injetável, tendo sido citados por 50 (100\%) das respondentes, seguidos pelo DIU (92\%), tabela (88\%), al eitamento materno (LAM) (84\%), coito interrompido $(76 \%)$ e preservativo feminino (66\%). Já a pílula de emergência, a temperatura basal e o espermicida foram os menos conhecidos, tendo sido ignorados por $84 \%, 74 \%$ e $64 \%$ das mulheres, respectivamente. 0 diafragma e o muco cervical também apareceram com um elevado percentual de desconhecimento, ou seja, de $62 \%$.

A água de aroeira foi referida como contraceptivo por $3(6 \%)$ mulheres: Dizem que é bom. Duas amigas minhas tomam há dois anos e não engravidam (U4). Toma um gole de aroeira e faz 
Tabela 1

Conhecimento das usuárias sobre os métodos anticoncepcionais reversíveis - Ceres Baturité (CE) jul./set. 2003.

\begin{tabular}{lcccccccc}
\hline Relação dos MAC & \multicolumn{2}{c}{$\begin{array}{c}\text { Citou o MAC } \\
\text { espontaneamente }\end{array}$} & \multicolumn{2}{c}{$\begin{array}{c}\text { Confirmou conhecer } \\
\text { o M AC após lembrado }\end{array}$} & \multicolumn{2}{c}{ Conheciam o M AC } & \multicolumn{2}{c}{ Não conheciam o MAC } \\
\hline & Fa & $\%$ & Fa & $\%$ & Fa & $\%$ & Fa & $\%$ \\
\hline Tabela & 13 & 26 & 31 & 62 & 44 & 88 & 06 & 12 \\
Muco & 01 & 2 & 18 & 36 & 19 & 38 & 31 & 62 \\
Temperatura basal & 00 & 00 & 13 & 26 & 13 & 26 & 37 & 74 \\
Coito interrompido & 01 & 2 & 37 & 74 & 38 & 76 & 12 & 24 \\
Aleitamento & 00 & 00 & 42 & 84 & 42 & 84 & 08 & 16 \\
Pílula & 48 & 96 & 02 & 04 & 50 & 100 & 00 & 00 \\
Injetável & 29 & 58 & 21 & 42 & 50 & 100 & 00 & 00 \\
DIU & 32 & 64 & 14 & 28 & 46 & 92 & 04 & 8 \\
Camisinha masculina & 48 & 96 & 02 & 4 & 50 & 100 & 00 & 00 \\
Camisinha feminina & 05 & 10 & 28 & 56 & 33 & 66 & 17 & 34 \\
Diafragma & 12 & 24 & 07 & 14 & 19 & 38 & 31 & 62 \\
Espermicida & 03 & 61 & 5 & 30 & 18 & 36 & 32 & 64 \\
Pílula de emergência & 00 & 00 & 08 & 16 & 08 & 16 & 42 & 84 \\
\hline
\end{tabular}

o asseio depois da relação (U 31, U 33). Uma dessas mulheres (U 33), além de referir a água de aroeira como método anticoncepcional afirmou que tomar a pílula do mato também evita a gravidez. Nenhuma evidência científica foi encontrada no sentido de justificar estes meios como contraceptivos. Todavia, em se tratando de asseio pós-coito, alguma ação mecânica poderá interferir na redução de chances da fecundação. N este sentido, o M S enfatiza que os profissionais devem estar familiarizados com mitos e percepções errôneas sobre os M AC para combatê- los com sensibilidade e de maneira correta (MS, 2002).

\section{O piniões das mulheres quanto à importância de planejar a família}

A informação adequada provoca um impacto no cliente, levando-o a elaborar suas próprias opiniões, tomar decisões e perceber-se na relação consigo, com a família, com a comunidade, enfim com o mundo. Neste contexto, as opiniões das usuárias quanto à importância de planejar a família foram identificadas e avaliadas.

Chamou nossa atenção o fato de que todas as mulheres associaram a importância do PF como meio para reduzir o número de nascimentos, talvez por serem usuárias do serviço de PF com a finalidade de promover a anticoncepção, ou pelo fato de o acesso a serviços voltados a apoiar a concepção estarem bem distan- tes delas. As falas mais freqüentes foram expressas por 20 (40\%) das usuárias que associaram a importância do PF à possi bilidade de ter poucos filhos, o que favorece as chances de garantir-Ihe conforto, bem-estar, educação e um futuro melhor; 14 (28\%) emitiram a opinião de que o PF ajuda a evitar o "sofrimento" causado pelas necessidades básicas insatisfeitas, principalmente relacionadas à escassez de alimentação, uma vez que oferece condições para se ter menos filhos; outras 9 (18\%) comentaram a respeito de não expor os filhos à violência que a sociedade enfrenta atualmente; e 4 (8\%) fizeram referência à prevenção de riscos à saúde materna. Apresentamos, a seguir, alguns dos depoimentos mais significativos que caracterizaram cada grupo de percepções e sentimentos expressos pelas mulheres.

\section{Possibilidade de oferecer conforto, bem-estar, educação e um futuro melhor aos filhos}

Este sentimento parece guardar uma relação com o mito do progresso que se instalou na consciência coletiva, associando a qualificação educacional como condição prevalente do desenvolvimento econômico-social, bem como a extrema valorização do conhecimento no cenário internacional (Arruda, 2002). Por outro lado, Scavone (2001) pressupõe que as mulheres que têm mais acesso à educação formal e à formação profissional fizeram a mater- 
nidade se tornar uma escolha reflexiva, possibilitada pela contracepção e concepção moderna. Todavia, esta justificativa não é adequada ao perfil das mulheres deste estudo, parecendo ser motivo maior de reflexão sobre a maternidade, as dificuldades de educação e trabalho que estas enfrentaram e enfrentam ao longo de suas histórias. As mulheres acreditam que a educação possa ser um caminho para que os filhos tenham melhores condições de inclusão social. Nos depoimentos listados na seqüência, podemos observar essa visão das mulheres.

Para planejar a família, a gente precisa pensar no número mínimo de filhos queé pra gente poder oferecer o bem-estar, a saúde e a educação (U1).

É importante dar educação, bom estudo. Quero pra eles a educação que eu não tive (U 7, U 14, U 15).

Eu queria que meus filhos tivessem o que eu não tive, estudassem, pudessem trabalhar. Só isso mesmo estava bom. $\mathrm{E}$ a gente tendo muitos filhos fica mais difícil, né? (U44).

\section{Poder evitar o "sofrimento" gerado por necessidades básicas insatisfeitas}

Este sentimento se mostrou a partir de experiências narradas sobre o cotidiano destas mulheres, associadas à falta de alimentos para seus filhos. Representou um dos momentos difíceis da pesquisa, uma vez que nos deparamos com emoções fortes das mulheres, expressas através de choro e revolta. Listamos a seguir os principais desabafos.

É bom evitar filho porque a nossa condição é baixa, falta até a alimentação. Eu me sinto mal em não dar o que meu filho pede (U6, U8).

... tem criança que sente a falta de alimentação. 0 meu mesmo chora por comer enão tenho o que dar [lágrimas] (U 10).

Não devemos botar criança no mundo pra sofrer, passar fome como muitos que a gente vê por aí (U21).

As crianças nascem não têm nem um pano pra cobrir (U33).

Eu pretendo não ter família agora. As coisas estão difícei s... falta o leite pra um [silêncio, tristeza], a gente só falta ficar doida (U 46).

\section{Não expor os filhos à violência que a sociedade hoje enfrenta}

Para M inayo (2003), a violência é hoje um problema de saúde pública, porque vem na contramão da qualidade de vida, impedindo a plena expressão do processo vital saudável, provocando medos, angústias, e ansiedades. A mesma autora acrescenta que cabe aos profissionais de saúde, incluindo o enfermeiro, atuar para a redução da violência social, em favor da vida e da inclusão social. Sobre este último item, o M S destaca a inter setorialidade como estratégia a ser adotada no PSF para estimular o desenvolvimento de ações conjuntas dos serviços de saúde e de outros órgãos públicos, bem como articular políticas e ações de interesse para a saúde, potencializando os recursos financeiros, tecnológicos, materiais e humanos disponíveis, evitando duplicidade de meios para idênticos fins (MS, 1998). Esse sentimento de temor à violência foi destacado nas falas descritas a seguir, nas quais as mulheres demonstraram uma preocupação com a violência externa relacionada às drogas e à exclusão social, bem assim como a violência domiciliar, intrafamiliar caracterizada nos conflitos entre pais e filhos.

A situação que está hoje em dia não tem como ter muitos filhos. As coi sas difíceis [ situação socioeconômica], o desemprego, a violência, as drogas (U 15). Temos o mundo das drogas, das violências (U35).

Eu acho muito bom porque uma criança planejada é bem-vinda. Quando a criança não é planejada, é maltratada. Conheço muitas mães que maltratam, dizem palavrão, aí a criança cresce revoltada, sem amor (U 48).

Hoje em dia os filhos não fazem mais conta dos pais, sem respeito, é melhor evitar (U50).

\section{Prevenção de riscos à saúde reprodutiva}

As mulheres associaram os benefícios do PF à prevenção de riscos reprodutivos, incluindo, todavia, a percepção quanto aos serviços oferecerem assistência integral. Hatcher et al. (2001) reiteram a idéia de que, através do planejamento familiar, muitas mulheres têm sido poupadas de gestações de alto risco em todo 0 mundo. Por outro lado, o M S enfatiza o aspecto da integralidade da assistência, independentemente do M AC escolhido ou da intenção da mulher de conhecê-lo ou não (M S, 1996). Nos relatos postos a seguir, as usuárias reconheceram a importância do PF como meio para garantir a saúde reprodutiva, evitando a gravidez de risco:

Da minha [refere-se à gravidez anterior] tive eclampsia, quase morro. Só quero uma mesmo (U13). 
Planejar o número de filhos hoje é necessário. Eu gostaria de ter três, mas vou parar nos dois. Também no último tive muitos problemas, muito sangramento, passou do tempo efiquei com medo (U31).

É importante para aprender como se evitar a gravidez e também as doenças, usar camisinha, abrir os ol hos porque os maridos são muito dana$\operatorname{dos}(\mathrm{U} 40)$.

\section{Considerações finais}

Na região do estudo, a informação dada ao cliente em PF ocorre, predominantemente, através da orientação individual realizada por enfermeiros. Apesar de ser uma oportunidade indiscutível para se estabelecer um adequado processo de orientação, tem limitado poder de alcance. Embora reconheçam a importância das atividades grupais e coletivas como estraté gias para informar em PF, os enfermeiros as realizam esporadicamente, apresentando a demanda superior à capacidade de atendimento como principal causa. Este aspecto, uma vez analisado, não justificou a omissão dos enfermeiros em priorizar as ações grupais. Essa iniciativa de dar prioridade às ações em grupo contribuiria até mesmo para dar respostas mais abrangentes à demanda excessiva. Todavia, há escassez de recursos materiais para apoiar as atividades de orientação e informação, a começar por um espaço físico adequado ao funcionamento de grupos.

A pílula, o preservativo masculino e o injetável foram os MACs mais conhecidos das mulheres entrevistadas, seguidos pelo DIU, a tabela e 0 aleitamento materno. M esmo assim, ficou constatada a necessidade de maior divulgação dessas informações.

Ressaltamos as percepções singulares descritas pelo grupo de mulheres entrevistadas, guardando informações de sentido bastante amplo sobre os benefícios do PF, com opiniões que vão além da esfera da contracepção ou da reprodução, aspecto que merece ser incorporado e mais bem valorizado nas informações em PF, como ação de promoção da saúde e de uma melhor qualidade de vida.

\section{Colaboradores}

ERF M oura e RM Silva realizou a fase exploratória da pesquisa, definindo objeto de estudo, objetivos e metodologia, coletou e organizou os dados. RM Silva participou de todas as etapas da pesquisa como orientadora.

\section{Referências bibliográficas}

Arruda BKG 2002. Um novo enfoque da educação médica. Revista Brasileira de Saúde M aterno-Infantil 2(2):8990.

Ávila M B \& Corrêa S 1999.0 movimento de saúde e direitos reprodutivos no Brasil: revisitando percursos, pp. 70-103. In L Galvão \& J Díaz (orgs.). Saúde sexual ere produtiva no Brasil: dilemase desafios. Editora Hucitec, São Paulo.

Bardin L 1977. Análise de conteúdo. Ed. Edições, Lisboa.

Bechelli LP \& Santos M A 2002. Psicoterapia de grupo e considerações sobre o paciente como agente da própria mudança. Revista Latino-Americana de Enfermagem 10(3):383-391

Bruce J 1990. Fundamental elements of the quality of care: a simple framework. Studies Family Planning 21(2):61-91.

Costa AM 2002. Planejamento familiar no Brasil. Disponível em <http://www.cfm.org.br/revista/bio2v4/ planeja.html>. Acesso em 6 dezembro 2002.

García-N úñez J 1993. Avaliação em planejamento familiar: um guia para administradores e avaliadores. Pathfinder Internacional, Salvador. 
Hatcher RA, Rinehart W, Blackburn R, Geller JS \& Shelton JD 2001. Pontos essenciais da tecnologia de anticoncepção. Escola de Saúde Pública Johns H opkins, Baltimore. Programa de Informação de População.

Kawamoto EE 1993. Educação em saúde, pp. 29-33. In EE Kawamoto. Enfermagem comunitária. EPU, São Paulo. Levy S 2000. Programa Educação em Saúde. Disponível em $<$ <ttp://www.saúde.gov.br/programas/pes/pes/index. htm>. Acesso em 22 outubro 2000

Lopes MV 2003. Contratação de médicos é difícil no interior, p. 2. Jornal Diário do N ordeste, 18 outubro 2003. Fortaleza.

M inayo CS 2003. Violência e saúde: entrevista. Revista Sustentação 4(11):3-5.

Ministério da Saúde 2002. Assistência em planejamento familiar: manual técnico. (4ª ed.). MS, Braślia.

M inistério da Saúde 2001. Guia prático do Programa Saú de da Família. MS, Brasília.

M inistério da Saúde 1998. Saúde da família: uma estraté gia para a reorientação do modelo assistencial. MS Brasília.
M inistério da Saúde 1996. Assistência ao planejamento familiar. MS, Brasília.

M oura ERF \& Sousa RA 2002. Educação em saúde reprodutiva: proposta ou realidade do programa saúde da família? Cadernos de Saúde Pública 18(6):1809-1811.

Scavone L 2001. M aternidade: transformações na família e nas relações de gênero. Interface - Comunicação, Saúde eEducação 5(8):47-60.

(SES-CE) Secretaria da Saúde do Ceará, 2003. Informe mimeografado. Núcleo de Organização da Atenção Primária. Fortaleza.

Sociedade Civil do Bem-Estar Familiar (Bemfam) 1996. Pesquisa nacional sobre demografia e saúde - PNDS. Rio de Janeiro.

Tyrrell M A \& Carvalho V 1995. Programas nacionais de saúde materno-infantil: impacto político social e inserção de enfermagem. UFRJ, Rio de Janeiro.

Trentini M \& Paim L 1999. Pesquisa em enfermagem: uma modalidade convergente-assistencial. UFSC, Florianópolis.

Artigo apresentado em 28/8/2004

Aprovado em 8/10/2004

Versão final apresentada em 18/10/2004 